\title{
Article
}

\section{Seeing and holding baby: Systematic review of clinical management and parental outcomes following stillbirth}

Kingdon, Carol, Givens, Jennifer, O'Donell, Emer and Turner, Mark Available at http://clok.uclan.ac.uk/12013/

Kingdon, Carol ORCID: 0000-0002-5958-9257, Givens, Jennifer, O'Donell, Emer and Turner, Mark (2015) Seeing and holding baby: Systematic review of clinical management and parental outcomes following stillbirth. Birth, 42 (3). pp. 206-218. ISSN 0730-7659

It is advisable to refer to the publisher's version if you intend to cite from the work. http://dx.doi.org/10.1111/birt.12176

For more information about UCLan's research in this area go to http://www.uclan.ac.uk/researchgroups/ and search for <name of research Group>.

For information about Research generally at UCLan please go to http://www.uclan.ac.uk/research/

All outputs in CLoK are protected by Intellectual Property Rights law, including Copyright law. Copyright, IPR and Moral Rights for the works on this site are retained by the individual authors and/or other copyright owners. Terms and conditions for use of this material are defined in the policies page. 


\title{
Seeing and holding baby: Systematic review of clinical management and parental outcomes following stillbirth
}

\begin{abstract}
Background In 2009 there were an estimated 2.6 million stillbirths worldwide. In the United States, a 2007 systematic review found little consensus about professional behaviours perceived by parents to be most helpful or most distressing. In the United Kingdom a bereaved parents' organisation has highlighted discordance between parental views and clinical guidelines that recommend clinicians' do not encourage parents to see and hold their baby. The objective of this review was to identify and synthesise available research reporting parental outcomes relating to seeing and holding.
\end{abstract}

Method(s) We undertook a systematic review. We included studies of any design, reporting parental experiences and outcomes. Electronic searches (PubMed, PsychINFO) were conducted in January 2014. Three authors independently screened and assessed the quality of the studies, before abstracting data and undertaking thematic analysis.

Results We reviewed 741 records and included 23 studies (10 quantitative,12 qualitative,1 mixed-method). Twenty-one studies suggested positive outcomes for parents who saw or held their baby. Increased psychological morbidity was associated with current pregnancy, choice not to see their baby, lack of time with their baby and/or insufficient mementos. Three themes were formulated "Positive effects of contact within a traumatic life event", "Importance of role of health professionals"; and "Impact on Mothers and Fathers: Similarities and differences".

Conclusions: Stillbirth is a risk factor for increased psychological morbidity. Parents' seeing and holding their stillborn baby can be beneficial to their future wellbeing. Since 2007, there has been a proliferation of studies that challenge clinical guidelines recommending clinicians do not encourage parental contact.

Keywords: review, stillbirth, seeing and holding

Word count: 3,998 

parental outcomes following stillbirth

\section{Background}

5 Worldwide, in 2009, approximately 2.6million stillbirths occurred(1). In recent years, 6 the United Kingdom's (UK) Royal College of Obstetricians and Gynaecologists 7 (RCOG)(2), National Institute for Clinical Excellence (NICE)(3), the American College 8 of Obstetrics and Gynaecology (ACOG)(4), and the Perinatal Society of Australia and 9 New Zealand (PSANZ)(5) have all issued new clinical guidance relating to the management of stillbirth. These guidelines include references to what is known about care practices that may help bereaved parents cope at the time and in the years following a stillbirth. The trauma of giving birth to a stillborn baby is known to greatly impact parents and their surrounding family $(6,7)$. Seeing and/or holding the baby is part of a number of psycho-social interventions around the time of stillbirth that may improve parents' short and long-term wellbeing(7). Other examples of interventions include adjustments to the physical environment, counselling, and making mementos, such as hand and foot prints. The attitudes and behaviour of clinicians' around the time of birth can greatly influence parents' decision-making.

In the UK, approximately 4,000 babies are stillborn each year(8). Current RCOG guidelines state 'carers should avoid persuading parents to have contact with their stillborn baby, but should strongly support such desires when expressed'(2), at the same time as national guidance recommends; 'mothers whose infants are stillborn or die soon after birth should not be routinely encouraged to see and hold the dead infant'(3). The publication of the latter guidance sparked a high profile 'seeing and 
holding your baby' campaign by the UK Stillbirth and Neonatal Death charity(9). In June 2010, following discussion with the Guideline Development Group a clarification statement was released, but to date the guidance remains the same. It is based on evidence published before 2009 , which suggests that seeing and holding the baby is not beneficial for everyone(3).

Compared to the volume of research into the aetiology and prevention of stillbirth there are relatively few studies investigating parental experience of stillbirth. In 2007, Gold published a systematic review of parent experiences of interactions with health providers' following stillbirth(10). That review examined numerous aspects of parents' experience, including interactions with staff, contact with the baby and the creation of mementoes. The author found that interactions with health professionals have profound effects on parents and concluded that health professionals may benefit from increased training in bereavement support. The review was inconclusive in relation to the benefits of parents seeing and holding their stillborn baby. In 2013, a Cochrane Review of 'Support for mothers, fathers and families after perinatal death' also concluded that the evidence of the potential detrimental effect of seeing and holding a deceased baby remains inconclusive(11). The Cochrane Review acknowledges that the sensitive nature of the topic makes developing trials difficult and rigorous research designs other than trials should inform practice in this area.

7 The rationale for the present review builds on Gold's(10) concern that there is little consensus about which behaviours are most helpful or harmful for bereaved parents at the time of stillbirth. In the UK this is evident in current guideline recommendations 
50 for seeing and holding, which run contrary to the suggestions of bereaved parent groups $(9,12)$. Seeing and holding is the explicit focus of our review. It aims to address the question "What is the evidence of benefit and harm for parents seeing and holding their baby following stillbirth after 20 or more completed weeks of pregnancy?"

\section{Methods}

The study design was a systematic review informed by the principles of narrative synthesis. At the time of writing there is on-going debate about how best to synthesize research using different methodologies in meaningful ways, which draws from a number of approaches $(14,15)$. Our approach follows the systematic steps common to many of these approaches but is not directly aligned to any particular one. In

\section{Search Strategy and Selection Criteria}

After initial scoping of the topic, a search strategy was designed to locate studies, of any methodological design, reporting parental views and experiences of seeing and holding their stillborn baby. All electronic searches were undertaken in January 2014, with an English language and human subjects restrictions imposed. No date restriction was placed on the search. Searches used the key words covering the main search domains including "seeing" OR "holding" OR "contact" AND "perinatal death" OR "pregnancy loss" OR "fetal death" OR "stillborn" OR "stillbirth" AND "grief" OR 
"bereavement" OR "psychology". The search strategy prioritised sensitivity over specificity to aim for completeness, which necessitated screening a large number of articles. Searches were conducted using PubMed and PsychINFO databases. We chose PubMed over Medline as it is inclusive of Medline, is more up-to-date and has a wider scope (including life science journals). We chose PsychINFO as the leading database for behavioural sciences and mental health. A handsearch was carried out using references obtained from the relevant papers. Two authors (EO, JG) initially reviewed all of the included papers independently, then together with the lead author to reach a final agreement on inclusion by consensus. Primary research papers reporting maternal and/or paternal data, following a stillbirth after 20 completed week's gestation were included. As there is no standardised definition of stillbirth(1) we imposed the lowest gestational limit used in clinical management(16). Included manuscripts had to be available and written in English. The full list of exclusion and inclusion criteria is shown in Figure 1.

\section{Quality Assessment}

Articles that met the inclusion criteria were independently assessed by three authors (EO,JG,CK) to minimise bias. Quality appraisal of quantitative studies was carried out using checklists from the Critical Appraisal Skills Programme (CASP) Toolkit(16). Checklists formed from this process were used to grade papers into categories $A, B$, C or D, with group A representing papers of the highest quality. Papers were assigned a group according to how many criteria it not fulfilled; e.g. Category A contained papers that had not fulfilled $0-1$ of the marked criteria whilst Category D contained the papers that had not fulfilled $\geq 6$ criteria. More weight was given to the presence of precise 
results than to presence of possible bias, as this is present in some form in most studies. Qualitative appraisal was conducted according to the checklist described by Walsh and Downe(17) and articles were graded according to Downe and Simpson(18). A grade of A was allocated to papers which had no or few flaws where the study credibility, transferability, dependability, and confirmability is high; B, some flaws, unlikely to affect the credibility, transferability, dependability, and/or confirmability of the study; C, some flaws which may affect the credibility, transferability, dependability, and/or confirmability of the study; D, significant flaws which are very likely to affect the credibility, transferability, dependability. One study that reported quantitative and qualitative data was assessed by combining two relevant checklists. Any differences in the authors' appraisals resulted in a re-read of individual papers and a decision was reached in unison by three authors. The final grading is listed in Table 1.

\section{Analysis and Synthesis}

This review generally adheres to the reporting strategy recommended by the Preferred Reporting Items for Systematic Reviews and Meta-Analyses (PRISMA)(19). However, not all recommendations were feasible given the wide degree of heterogeneity both within and across research traditions. None of the quantitative studies were suitable for meta-analysis - Table 2 summarises their outcome measures, analytic strategies, and key findings. Instead this review replicates the reporting structure of Gold's systematic review with studies summarised narratively by tradition (quantitative or qualitative) and synthesised in relation to three overarching themes(10). The themes are "'Positive effects of contact within a traumatic life event", "Importance of role of 
122 health professionals"; and "Impact on Mothers and Fathers: Similarities and differences". These themes were formulated based on consensus agreement by all authors about shared and discrepant findings across all included studies.

\section{Results}

\section{Search Outcomes}

The search strategy yielded 735 results containing quantitative, qualitative and mixed methods papers. Six additional records were identified through other sources (hand searching and reference lists). A total of 637 records were independently screened and excluded by title or abstract. One hundred full-text articles required assessment for eligibility. These processes resulted in 706 exclusions, leaving 31 articles requiring assessment for methodological quality. Eight papers were excluded at this point.

\section{Description of included studies}

A total of 23 papers are included in this review(20-42). They incorporate 10 quantitative papers(20-29), 12 qualitative papers(31-42) and one mixed methods study(30). Nine studies originated from Sweden, five from the United Kingdom, five from the United States, one from Canada, one from Norway, one from Australia and one from Japan. The earliest included paper was published in 1983(31). Fourteen of the studies were published in or after 2007(24-30,36-42). This figure includes seven of the 12 qualitative studies(36-42). In total, the 23 studies involved 4,529 participants, 
including controls. Four Swedish studies(21,22,24,27), three US studies(30,36,38) and two UK studies $(23,26)$ included data from the same individuals who were followed up in a subsequent study or different aspects of data from the same study were reported in separate papers. Three studies $(32,33,40)$ looked solely into male perspective following stillbirth with a further three examining the experience in couples $(20,34,42)$. Marital status was reported in ten studies. $(20,21,23,26,29,32-$ $34,37,42)$. Although all papers included information on seeing and holding stillborn babies, eight of the studies did not state the number of participants that saw their

\section{Seeing and holding: Positive effects of contact within a traumatic life event}

With the exception of two quantitative papers $(23,26)$, all other papers reported positive outcomes and experiences of parents' contact with their stillborn baby (20-22,24-42). Five quantitative papers $(21,23,26,27,29)$ commented on possible adverse outcomes associations $(23,26)$. Both of these studies were authored by the same UK team and involved the same participants. The first study(23), a retrospective case-control study involving 65 pregnant women with a history of previous stillbirth found a narrowly nonsignificant $(p=0.06)$ association between seeing and holding, length of time since loss and third trimester depression in current pregnancy. In this study 17 women did not see their stillborn baby; 14 saw but did not hold their stillborn baby, and 34 had held their stillborn baby. Compared to controls, all women who had experienced a stillbirth 
had significantly greater post-traumatic stress disorder (PTSD) in the third trimester of a subsequent pregnancy, irrespective of whether or not they had seen or held their stillborn baby. The second study(26) was a seven year follow-up of study of the same participants that reported an association between mothers having held their stillborn baby, case-level PTSD and subsequent partnership breakdown. Whilst the first study(23) shows evidence of psychological hardships during future pregnancies, another study(25) suggests that these associations may be transient; resolved when a subsequent pregnancy ends with a live birth.

Four of the quantitative studies included in this review reported either no significant difference in anxiety or depressive symptoms of parents who had seen or held their stillborn baby compared to those who had not $(21,24)$ or, increased risks of mental health outcomes associated with no contact(27,29). Rådestad et al(21) found that increased anxiety and depression was associated with a lack of tangible tokens for remembrance and not seeing the baby for as long as parents had wished. Contact with the baby in itself did not cause an increase in symptoms. Crawley et al(29) also found that making memories was not associated with adverse outcomes for parents, but rather a lack of memories and barriers to talking about the experience of stillbirth was significantly associated with mental health outcomes. Another paper, Cacciatore et al(25) reports amongst non-pregnant women who saw their stillborn baby, lower not higher, levels of anxiety and depression were present. Among pregnant women assessed during a pregnancy after the stillbirth there was an increased risk of anxiety and a tendency towards depression. 
One study conducted in the US in 1994(21) reported that $95.5 \%$ of parents that had seen their baby thought it was essential. A more recent international survey $(n=2,292)$, where the majority of respondents were from the US (72\%), reported amongst the $95 \%$ of women who saw their baby, $99.7 \%$ were glad to have done so; and amongst the $90 \%$ of women who had held their baby $99.5 \%$ of mothers were glad to have done so. Amongst the women who did not see or hold their baby $80 \%$ regretted this, even though the decision was their choice. Further insight into the complexities of the choices available to individual parents at the time of stillbirth is offered by Rådestad et al(27) who report a beneficial effect of having held a stillborn baby after 37 gestation weeks, whilst the effects between 28-37 weeks are uncertain. The qualitative studies offer more detailed insight into these complexities. They suggest that parents perceive contact positively, even if they are initially reluctant to see or hold their baby.

A recurring finding across the quantitative and qualitative papers was that parent's view seeing and holding as helpful to come to terms with their loss. Contact following the birth was the only time they had to create memories of their child. One quantitative(25), one mixed method(30) and three qualitative studies(32,35,37) addressed participants having regrets about decisions made following stillbirth. The main focus of regret was not seeing and holding their child as well as not creating enough tangible memories, for example, photographs and footprints. In a paper by Trulsson et al(35), all women had seen their baby with three of these finding the experience frightening at first but ultimately comfortable and none of the participants regretted seeing their baby. Many parents expressed regret with regard to the length of time spent with the infant in the hours following the birth $(21,24,30,34,35,38,39)$. 
developing symptoms of depression or anxiety were found to have increased seven fold three years post-delivery in one study(22). Qualitative findings from five studies $(30,34,35,38,39)$ support this.

\section{Importance of role of health professionals}

Many studies reported parents' gratitude for the support they were given by health professionals around the time of stillbirth. Nine papers suggested the scope for increased guidance by health professionals to help parents decide whether or not to see and hold their baby. Six of these were qualitative studies $(31,33,34,35,36,42)$ and three were quantitative $(25,27,28)$. A recurrent finding in the six qualitative papers $(31,33,34,35,36,42)$ highlighted that in this time of grief, some parents preferred the health care professional to lead them to a decision that was "right." Across three decades and two continents if the midwife described the baby as beautiful, women felt validated as a mother and as a result were more likely to see their infant $(31,39,41)$. One quantitative study described how a lack of healthcare support resulted in women being four times less likely to hold the stillborn(27), underlining the influence of professionals in decision making. Two papers $(25,28)$ examined the way in which staff facilitate seeing and holding and the parental impact. Erlandsson et al(28) studied 668 participants who responded to how the baby was presented at birth. The group who were assumptively offered the baby (with no prior discussion), most commonly reported that they were not at all frightened $(p=0.02)$ or uncomfortable $(p<0.01)$ seeing the stillborn compared to the group who were asked. In addition, there was a trend that mothers felt more natural and good if the baby was offered to them without being asked, however this was not statistically significant $(p=0.07)$. The study by Cacciatore(25) with a large study sample of 2,292, found that those who were 
assumptively given the child had significantly less depression symptoms than those who were offered as a choice $(p=0.035)$.

Parents felt that they were treated inadequately when healthcare professionals appeared dismissive of their stillborn baby. Behaviours that were appreciated by parents were acknowledging the child, calling the stillborn child by their name and not treating the child like an object but rather a live baby. Decreased satisfaction with professionals was found to be associated with an increase in PTSD and depressive symptoms in parents(29). Four studies(31,33,40,41) specifically mentioned about creating mementoes even if parents refused the offer at the time. Many parents stated that in hindsight, they were glad the midwife had created mementoes and kept them in the patient's notes so that the decision made after birth was not final.

In the study by Trulsson et al(35), five participants reported that on diagnosis of stillbirth, verbal communication deteriorated and parents expressed the feeling of isolation. It was noted that options should be provided both orally and in writing as it is difficult for parents to take in information when receiving bad news. Parents in one study suggested the need for discussing options before the birth such as bringing a camera and how the stillborn body may change post-delivery(38).

\section{Mother and Fathers: Similarities and Differences}

Stillbirth is a process that both mothers and fathers go through. However, the physiological aspects of the process are felt most by the mother and perhaps understandably most literature focuses on the experiences and outcomes of stillbirth 
contain information on reactions of fathers during stillbirth. Participants in three papers stated that fathers go through the same feelings of shock, grief and denial on receipt of the news of their child's death as mothers $(32,33,39)$ suggesting the need for a similar level of psychosocial care for fathers as for mothers(39). Men in one paper(40) expressed feeling a need to 'get rid' of the baby as soon as possible following diagnosis of intrauterine death, a reaction that was echoed by women in a paper by Trulsson et al(22). As has been demonstrated with mothers, males were grateful for staff support of their parenthood, including the treatment of their baby $(33,40)$ and tokens of remembrance, which were cherished as tangible proof that the child had existed $(32,33,40)$. In one paper(33) fathers expressed fear for their partners delivering the stillborn baby and seeing the baby after birth. In three studies $(32,33,37)$ fathers were found to feel the need to support their partners, as women appear more visibly upset, rather than address their own emotional needs during this incredibly traumatic time for both parents.

\section{Discussion}

This review sought to answer the question "what is the evidence of benefits and harms in relation to parents seeing and holding their stillborn baby?" A similar systematic review was published in $2007(10)$. We identified a proliferation of papers specifically concerned with seeing and holding that have been published in the intervening years. We found almost all included studies (21 out of 23) reported positive benefits for parents who had seen or held their baby. Five studies suggested the potential for harm, with two reporting an association. One of these two studies(23) was particularly influential in challenging the then norm for clinicians to encourage parents to see their stillborn baby, which led to a shift in clinical guidelines(2,3). Two subsequent studies 
have explicitly challenged the findings of that study $(24,25)$. The earlier review by Gold(10) was inconclusive in relation to the benefits of parents seeing and holding their stillborn baby, as was a more recent Cochrane Review(11). Our findings suggest that seeing and holding the stillborn baby is beneficial, the role of healthcare professionals in facilitating actual decision-making is key, women who have seen or held their stillborn baby should have additional support in any future pregnancies, and clinical management needs to take account of both parents' needs. These findings support the suggestion that good practices identified by family support groups should be included in professional guidelines. Specifically the principles of good practice set out by SANDS in the UK(12) and the unified position statement on contact with the baby published by the International Stillbirth Alliance(43).

Future guideline development should take into account that seeing and holding is beneficial for many parents when considered as part of positive memory making. Caring for parents experiencing stillbirth is known to be one of the more difficult aspects of maternity professionals roles(44-49). This review(20-42) adds weight to Gold's(10) principal finding that interactions with health professionals have profound effects on parents with perinatal losses. Many studies report interactions with healthcare professionals as the determining influence as to whether or not parents saw or held their baby. Current clinical guidelines place responsibility for the decisionmaking surrounding seeing and holding with the parents $(2,3)$. However, quantitative and qualitative studies included in this review show some parents express the need for increased guidance in making difficult decisions following the diagnosis of stillbirth, directly challenging some current guidelines. We suggest the balance of evidence has shifted for two reasons; an increase in studies in this area (of any design) and in 
particular an increase in the number of robust qualitative studies. Traditionally qualitative studies have not featured in medicine's hierarchies of evidence that are used in the formulation of clinical guidelines. However, qualitative research and synthesis is now routinely assessed for quality in similar (albeit philosophically different) ways as quantitative research and efforts to secure its inclusion in evidence based medicine are gaining momentum(50,51). The present review differs from the recent Cochrane Review (11) in both its question and methodology. The focus of the Cochrane Review was broader with the explicit objective of determining the effectiveness any form of intervention on parents and families who experience perinatal death. This review specifically focused on seeing and holding. The inclusion criteria for the Cochrane review were randomised controlled trials, whereas this review, following Gold (10), did not exclude studies on design alone. As previously highlighted in the introduction, the sensitive nature of this topic makes developing trials difficult and other rigorous research designs should also inform practice.

Another development since Gold(10) is that the experiences of fathers during pregnancy, childbirth and the immediate postnatal period have received increasing research attention(53). This review included six studies of fathers experiences of stillbirth, four of which were published since $2007(37,39-41)$. Male reactions to stillbirth appear to be very similar to that of women and psychosocial care should be directed at fathers at the same time as mothers. It has been found to be important to acknowledge the male in his role as a father and provide an opportunity for them to speak about the birth away from their partners whom they feel obliged to support. In the UK current RCOG guidelines' already acknowledge mothers, partners and siblings are all impacted and their reactions may be very different. 
344 The results of this paper must be interpreted in light of its limitations. Future search

345 strategies could be enhanced by searching a more exhaustive list of electronic databases including EMBASE and others with non-English language coverage such as African Journals on-line (AJOL) and LatIndex. It is an important limitation of this review that it excluded non-English language papers. We also employed strict exclusion criteria in respect of gestation age. Three papers were excluded because they did not state gestational age(54-56). A further six papers were excluded because results were not categorised by gestational age and the authors were unable to determine the results corresponding to births $>20$ weeks gestation(57-62). This review is suggestive of the importance of individual factors including gestational age on the variable benefits of seeing and holding for parents. Further research is required. The strengths of this review include a systematic search strategy and rigorous critical appraisal. It contributes to an emotive and controversial area of maternity practice in which professional and parent interactions fundamentally impact short and long-term outcomes for families.

\section{Conclusion}

Stillbirth is a risk factor for increased psychological morbidity. Since 2007 , there has been a proliferation of studies that challenge clinical guidelines recommending clinicians do not encourage parental contact. This review suggests parental contact with their stillborn baby is beneficial for many parents future wellbeing. This finding runs contrary to some current clinical guidelines, but resonates with the practice recommendations of bereaved parents' organisations. 


\section{References}

1. Cousens S, Blencowe H, Stanton C, Chou D, Ahmed S et al. (2011) National, regional, and worldwide estimates of stillbirth rates in 2009 with trends since 1995: a systematic analysis. The Lancet 377: 1319-30.

2. Royal College of Obstetricians and Gynaecologists. Late Intrauterine Fetal Death and Stillbirth. Guideline No.55. 2010.

3. National Institute for Health and Clinical Excellence. Antenatal and Postnatal Mental Health. Clinical Guideline 45. 2007. http://www.nice.org.uk/nicemedia/live/11004/30431/30431.pdf (accessed 24 Feb 2014).

4. American College of Obstetricians and Gynaecologists. Management of Stillbirth. Guideline No. 102. 2009.

5. Flenady V, King J, Charles A, et al. (2009) PSANZ clinical practice guideline for perinatal mortality. Version 2.2 April 2009.

www.stillbirthalliance.org.au/guideline1.htm (accessed 2/5/14).

6. Bennett SM, Litz BT, Lee BS, Maguen S. The Scope and Impact of Perinatal Loss: Current Status and Future Directions. Professional Psychology: Research and Practice. 2005; 36(2):180-187.

7. Cacciatore J. (2011) Psychosocial Care in Spong CY (ed) Stillbirth: Prediction, Prevention and Management. Blackwell, Chichester. Pg 203-228.

8. Confidential enquiry into maternal child health. Perinatal mortality 2008 : England, Wales and Northern Ireland. London: Centre for Enquiries into Maternal and Child Health, 2010. 
9. Stillbirth and Neonatal Death Charity (SANDS). Bereavement Care Report (2010). http://uk-sands.org/sites/default/files/SANDS-BEREAVEMENT-CAREREPORT-FINAL.pdf (accessed 3 March 2014).

10. Gold KJ. (2007) Navigating care after a baby dies: a systematic revie of parent experiences with health providers. Journal of Perinataloogy 27: 230237.

11. Koopmans L, Wilson T, Cacciatore J, Flenady V. (2013) Support for mothers, fathers and families after perinatal death. Cochrane Database of Systematic Reviews. Issue 6. Art. No.: CD000452.

12. Kohner N, Henley A (2001) When a baby dies: The experience of late miscarriage, stillbirth and neonatal death. Routledge, Abingdon.

13. Mays, N., Roberts, E. and Popay, J. (2001) Synthesising research evidence. In: Fulop, N., Allen, P., Clarke, A. and Black, N. (eds). Studying the organization and delivery of health services. London: Routledge.

14. Noyes J, Booth A, Hannes K, Harden A, Harris J, Lewin S, Lockwood C (editors), Supplementary Guidance for Inclusion of Qualitative Research in Cochrane Systematic Reviews of Interventions. Version 1 (updated August 2011). Cochrane Collaboration Qualitative Methods Group, 2011. Available from URL http://cqrmg.cochrane.org/supplemental-handbook-guidance.

15. Li Z, McNally L, Hilder L, Sulivan E (2011) Australia's mothers and babies 2009, Perinatal statistics series no.25 Cat. No. PER 52. Sydney: AIHW National Perinatal Epidemiology and Statistics Unit.

16. Critical Appraisal Skills Programme (CASP). CASP Checklists. 2013. http://www.casp-uk.net/\#!casp-tools-checklists/c18f8 (accessed 3 March 2014). 
17. Walsh D, Downe S. Appraising the quality of qualitative research. Midwifery. 2006;22:108-119.

18. Downe S, Simpson L, Trafford K. Expert intrapartum maternity care: a metasynthesis. Journal of Advanced Nursing. 2007;57(2):127-140. doi: 10.1111/j.1365-2648.2006.04079.x

19. Moher D, Liberati A, Tetzlaff J, Altman DG. (2008) The PRISMA Group. Preferred reporting items for systematic reviews and meta-analyses: The PRISMA Statement. PLoS Med2008;6:e1000097.

20. Lasker JN, Toedter LJ. Satisfaction with hospital care and interventions after pregnancy loss. Death Studies. 1994;18:41-64.

21. Rådestad I, Steineck G, Nordin C, Sjögren B. Psychological complications after stillbirth-influence of memories and immediate management: population based study. BMJ. 1996;312:1505-1508.

22. Rådestad I, Nordin C, Steineck G, Sjogren B. Stillbirth is No Longer Managed as a Non-event: A Nationwide Study in Sweden. BIRTH. 1996;23(4):209-215.

23. Hughes P, Turton P, Hopper E, Evans CDH. Assessment of guidelines for good practice in psychosocial care of mothers after stillbirth: a cohort study. Lancet. 2002; 360: 114-118.

24. Surkan PJ, Rådestad I, Cnattingius S, Steineck G, Dickman PW. Events after Stillbirth in Relation to Maternal Depressive Symptoms: A Brief Report. BIRTH. 2008;35(2):153-157.

25. Cacciatore J, Rådestad I, Frøen F. Effects of Contact with Stillborn babies on Maternal Anxiety and Depression. BIRTH. 2008; 35(4):313-320. 
26. Turton P, Evans C, Hughes P. Long-term psychosocial sequealae of stillbirth: phase II of a nested case-control cohort study. Arch Womens Ment Health. 2009;12:35-41.

27. Rådestad I, Surkan PJ, Steineck G, Cnattingius S, Onelöv E, Dickman P. Long-term outcomes for mothers who have or have not held their stillborn baby. Midwifery. 2009; 25:422-429.

28. Erlandsson K, Warland J, Cacciatore J, Rådestad I. Seeing and holding a stillborn baby: Mothers' feelings in relation to how their babies were presented to them after birth-Findings from an online questionnaire. Midwifery. 2013;29:246-250.

29. Crawley R, Lomax S, Ayers S. Recovering from stillbirth: the effects of making and sharing memories on maternal mental health. Journ Reprod Inf Psych. 2013;31(2):195-207.

30. Cacciatore J. Effects of support groups on Post Traumatic Stress Responses in Women experiencing Stillbirth. OMEGA. 2007; 55(1):71-90.

31. Lovell A. Some questions of identity: Late miscarriage, Stillbirth and Perinatal Loss. Soc. Sci. Med. 1983; 17(11): 755-761.

32. Worth NJ. Becoming a Father to a Stillborn Child. Clin Nurs Res. 1997;6(1):71-89.

33. Samuelsson M, Rådestad I, Segesten K. A Waste of Life: Fathers' Experience of Losing a Child Before Birth. BIRTH. 2001; 28(2):124-130.

34. Säflund K, Sjögren B, Wredling R. The Role of Caregivers after a Stillbirth: Views and Experiences of Parents. BIRTH. 2004; 31(2):132-137.

35. Trulsson O, Rådestad I. The Silent Child-Mothers' Experiences Before, During, and after Stillbirth. BIRTH. 2004;31(3):189-195. 
36. Cacciatore J, Bushfield S. Stillbirth: The Mother's Experience and Implications for Improving Care. Journal of Social Work in End-of-Life \& Pallative Care. 2007;3(3):59-79.

37. Yamazaki A. Living with Stillborn Babies as Family Members: Japanese Women who experienced Intrauterine Fetal Death after 28 weeks gestation. Health Care for Women International. 2010; 31:921-937.

38. Cacciatore J. The Unique Experiences of Women and Their Families After the Death of a Baby. Social Work in Health Care. 2010;49:134-148.

39. Lathrop A, VandeVusse L. Affirming Motherhood: Validation and Invalidation in Women's Perinatal Hospice Narratives. BIRTH. 2011;38(3):256-265.

40. Cacciatore J, Erlandsson K, Rådestad. Fatherhood and suffering: A qualitative exploration of Swedish Men's experiences of care after the death of a baby. Int Journ Nurs Stud. 2013;50:664-670.

41. Lee C. 'She was a person, she was here': The experience of late pregnancy Ioss in Australia. Journ Reprod Inf Psych. 2012; 30(1):62-76.

42. Downe S, Schmidt E, Kingdon C, Heazell AEP. Bereaved parents' experience of stillbirth in UK hospitals: a qualitative interview study. BMJ Open. 2013; 3:e002237. Doi:10.1136/bmjopen-2012-002237.

43. Warland J, Davis DL, et al (2011) Caring for Families Experiencing Stillbirth: A unified position statement on contact with the baby. An international Collaboration.

44. Jonas-Simpson CF, Pilkington B, MacDonald C, McMahon E. (2013) Nurses' Experiences of Grieving When There Is a Perinatal Death. SAGE Open. DOI: 10.1177/2158244013486116 (Accessed 19 May 2014) 
45. Wallbank S, Robertson N. (2013) Predictors of staff distress in response to professionally experienced miscarriage, stillbirth and neonatal loss: A questionnaire study. International Journal of Nursing Studies. 50:1090-1097.

46. Roehrs C, Masterson A, Alles R, Witt C, Rutt P. (2008) Caring for families coping with perinatal loss. Journ Obstet Gynae Neonatal Nurs. 37(6):631-639.

47. Chan MF, Lou FL, Zang YL, Chung YF, Wu LH et al (2007) Attitudes of midwives towards perinatal bereavement in Hong Kong. Midwifery. (3):309_ 21.

48. Gold KJ, Kuznia AL, Hayward RA. (2008) How physicians cope with stillbirth or neonatal death: a national survey of obstetricians. Obstet Gynecol. 112:29 34.

49. Downe S, Kingdon C, Kennedy R, Norwell H, McLaughlin MJ et al (2012) Post-mortem examination after stillbirth: views of UK-based practitioners. Eur J Obstet Gynecol Reprod Biol. 162:33-7.

50. The Joanna Briggs Institute Levels of evidence and Grades of Recommendation of Working Party. Supporting Document for the Joanna Briggs Institute Levels of Evidence and Grades of Recommendation. The Joanna Briggs Institute [Internet] 2014. Avaliable from: www.joannabrigs.org

51. Glenton C, Colvin CJ, Carslen B, Swartz A, Lewin S et al (2013) Barriers and facilitators to the implementation of lay health worker programmes to improve access to maternal and child health: qualitative evidence synthesis. Cochrane Database of Systematic Reviews 2013, Issue 10. Art.No.: CD01414. DOI 10.1002/14651858.CD010414.pub2. 
52. Royal College of Obstetricians and Gynaecologists (1995) Report of the RCOG working party on the management of perinatal deaths. London: Chameleon Press.

53. Steen, M., Downe, S., Bamford, N., \& Edozien, L. (2011). Not-patient and notvisitor: a metasynthesis of fathers encounters with pregnancy, birth and maternity care. Midwifery, 28(4), 422-431.

54. Kelley MC, Trinidad SB. Silent loss and the clinical encounter: Parent' and physicians' experiences of a stillbirth - a qualitative analysis. BMC Pregnancy and Childbirth. 2012;12:137.

55. Kuti O, Ilesanmi CE. Experiences and needs of Nigerian women after stillbirth. Int Journ Gynae Obs. 2011;113:205-207.

56. Bonnette S, Broom A. On Grief, fathering and the male role in men's accounts of stillbirth. Journ Soc. 2011:48(3):248-265.

57. Thompson S, Estrada M, Yonekura M. Factors affecting psychological adjustment to fetal death. Am J Obstet Gynecol.1987;157(2):254-257.

58. Bach Hughes C, Page-Liberman J. Fathers experiencing a perinatal loss. Death studies. 1989;13(6):537-556.

59. Kavanaugh K, Hershberger P. Perinatal loss in Low-Income African American Parents. JOGNN. 2005;34:595-605.

60. Cahen L, Zilkha S, Middleton RN et al. Perinatal moratility: Assisiting parental affirmation. Amer. J. Orthopsychiat. 1978;48(4):727-731.

61. Kellner KR, Donnelly WH, Gould SD. Parental Behaviour after Perinatal Death: Lack of Predictive Demographic and Obstetric Variables. Obstet Gynecol. 1984;63(6):809-814. 
62. Rand CSW, Kellner KR, Revak-Lutz et al. Parental behaviour after perinatal death: twelve years of observations. J Psycosom Obstet Gynecol. 1998;19:44-48. 
Figure 1: Process of article selection with inclusion and exclusion criteria

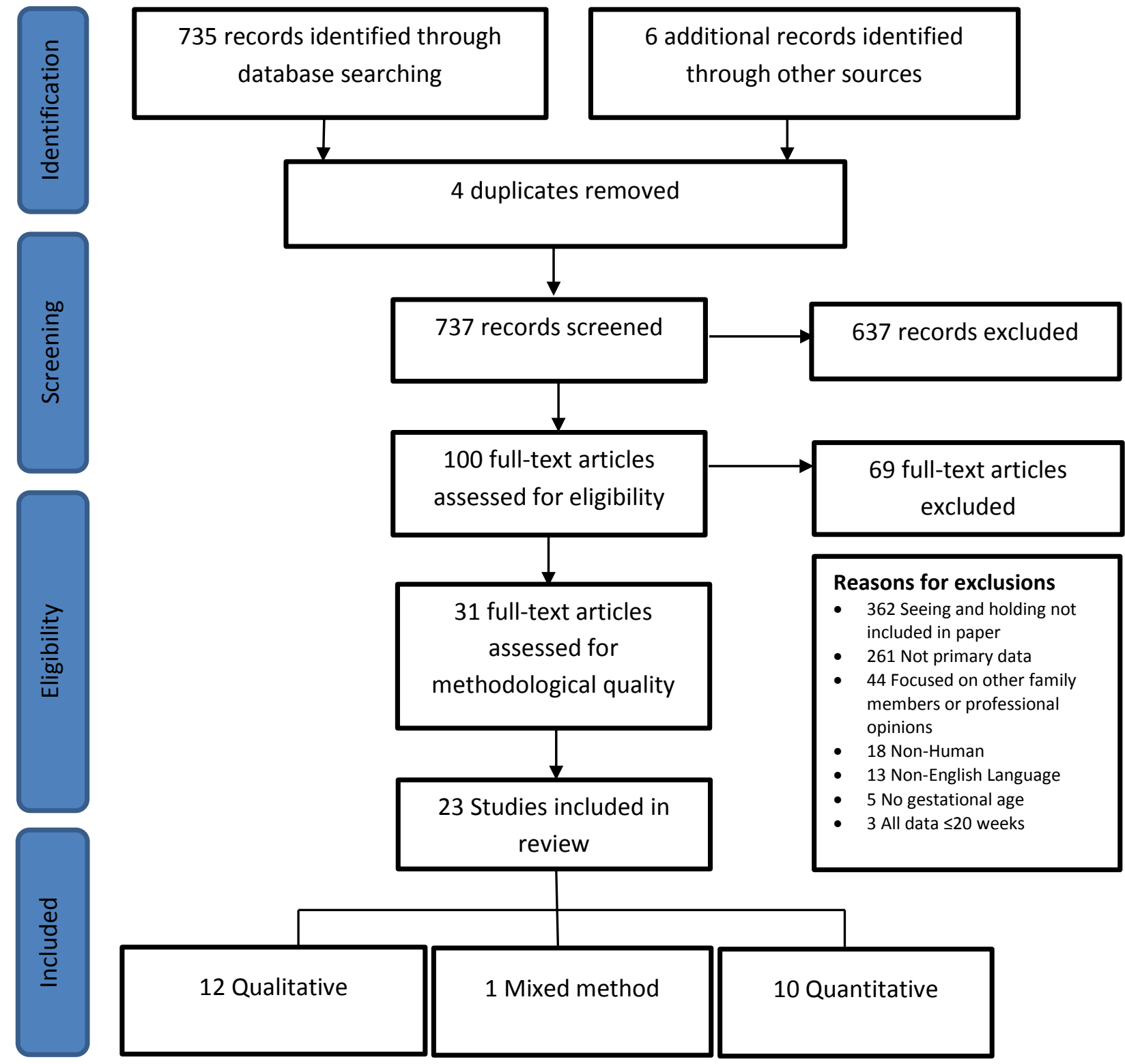

\begin{tabular}{|l|}
\hline Inclusion Criteria: \\
- Human data \\
- English Language \\
- Mull manuscript available \\
- Gestational age >20 completed weeks \\
- Unplanned Loss (no termination of \\
- Must include "seeing" and "holding" \\
\hline
\end{tabular}

Exclusion Criteria:

- Not written in the English language

- Does not contain "seeing" and "holding"

- All data involving stillborns of $<20$ weeks gestation

- Not primary data

- Viewpoints of other family members 
Table 1: Summary of Included Studies

\begin{tabular}{|c|c|c|c|c|c|c|c|}
\hline & Year & Location & Number of participants & Gestational Age & Length of time since Stillbirth & Method Used & Quality Grading \\
\hline \multicolumn{8}{|l|}{ Quantitative Studies } \\
\hline Lasker and Toedter (20) & 1994 & USA & 138 & $\geq 27$ weeks $n=22$ & $\begin{array}{l}\text { Followed up at } 2 \text { months, } 1 \text { year and } 2 \text { years } \\
\text { following loss }\end{array}$ & $\begin{array}{l}\text { Longitudinal cohort } \\
\text { study }\end{array}$ & B \\
\hline Rådestad et al (21) & 1996 & Sweden & 636 (314 stillbirth cases) & $\geq 28$ weeks & $\leq 4$ years & Case-control study & A \\
\hline Rådestad et al (22) & 1996 & Sweden & 636 who participated in (21) & $\geq 28$ weeks & $\leq 4$ years & Postal questionnaire & C \\
\hline Hughes et al (23) & 2002 & UK & 125 (65 stillbirth cases) & $\geq 18$ weeks & Not stated & $\begin{array}{l}\text { Case-Control Cohort } \\
\text { study }\end{array}$ & C \\
\hline Surkan et al (24) & 2008 & Sweden & $\begin{array}{l}314 \text { women who experienced } \\
\text { stillbirth and participated in (21) }\end{array}$ & $\geq 28$ weeks & 3 years & Postal questionnaire & $B$ \\
\hline Cacciatore et al (25) & 2008 & International & 2,292 & $\geq 20$ weeks & Not stated & Web-questionnaire & A \\
\hline Turton et al (26) & 2009 & UK & $\begin{array}{l}51 \text { controls and } 52 \text { cases who } \\
\text { participated in (23) }\end{array}$ & $\geq 18$ weeks & Not stated & Nested Case-Control & C \\
\hline Rådestad et al (27) & 2009 & Sweden & $\begin{array}{l}314 \text { women who experienced } \\
\text { stillbirth and participated in }(21,22 \\
\text { and 24) }\end{array}$ & $\geq 28$ weeks & $\leq 4$ years & Cohort Study & B \\
\hline Erlandsson et al (28) & 2013 & Sweden & 840 & $\geq 22$ weeks & $\begin{array}{l}\leq 1989(n=119) \\
1990-1999(n=106) \\
2000-2010 \quad(n=574) \\
\text { Not stated }(n=41)\end{array}$ & Web-questionnaire & A \\
\hline Crawley et al (29) & 2013 & UK & 162 & $\geq 20$ weeks & $\leq 10$ years & Web-questionnaire & A \\
\hline \multicolumn{8}{|l|}{ Mixed-Method Study } \\
\hline Cacciatore (30) & 2007 & USA & 47 & $\geq 20$ weeks & $\begin{array}{l}\text { Within } 1 \text { year }(n=10) \\
1-2 \text { years }(n=10) \\
2-5 \text { years }(n=17) \\
5-10 \text { years }(n=7) \\
\geq 10 \text { years }(n=3)\end{array}$ & Web-questionnaire & B \\
\hline
\end{tabular}


Qualitative Studies

\begin{tabular}{|llllll|}
\hline Lovell (31) & 1983 & UK & $\begin{array}{l}22 \text { mothers } \\
10 \text { stillbirths }\end{array}$ & $20-27$ weeks & Not stated \\
\hline Worth (32) & 1997 & Canada & 8 fathers & $26-41$ weeks & 3months-5years, 3 months \\
\hline Samuelsson et al (33) & 2001 & Sweden & 11 fathers & $33-42$ weeks & $5-27$ months \\
& & & & Interview & Interview \\
\hline Saflund et al (34) & 2004 & Sweden & $\begin{array}{l}24 \text { couples } \\
7 \text { mothers }\end{array}$ & B & Interview \\
\hline
\end{tabular}

\begin{tabular}{|c|c|c|c|c|c|c|c|}
\hline Trulsson and Rådestad (35) & 2004 & Sweden & 12 mothers & $\geq 24$ weeks & $6-18$ months & Interview & $B$ \\
\hline Cacciatore and Bushfield (36) & $2007 \mathrm{~b}$ & USA & 47 mothers & $\begin{array}{l}\text { 20-32 weeks }(n=13) \\
33-36 \text { weeks }(n=12) \\
\geq 37 \text { weeks }(n=22)\end{array}$ & $\begin{array}{l}\text { Within } 1 \text { year }(n=10) \\
1-2 \text { years }(n=10) \\
2-5 \text { years }(n=17) \\
5-10 \text { years }(n=7) \\
\geq 10 \text { years }(n=3)\end{array}$ & Questionnaire & $B$ \\
\hline Yamazaki (37) & 2010 & Japan & 17 mothers & 28-40 weeks & $1-6$ years & Interview & A \\
\hline Cacciatore (38) & $2010 c$ & USA & 47 mothers & $\begin{array}{l}\text { 20-32 weeks }(n=13) \\
33-36 \text { weeks }(n=12) \\
\geq 37 \text { weeks }(n=22)\end{array}$ & $\begin{array}{l}\text { Within } 1 \text { year }(n=10) \\
1-2 \text { years }(n=10) \\
2-5 \text { years }(n=17) \\
5-10 \text { years }(n=7) \\
\geq 10 \text { years }(n=3)\end{array}$ & Questionnaire & $B$ \\
\hline Lanthrop and VandeVusse (39) & 2011 & USA & 15 mothers & 28-36 weeks & $\begin{array}{l}1-2 \text { years }(n=5) \\
2-4 \text { years }(n=3) \\
5-9 \text { years }(n=7)\end{array}$ & Interview & A \\
\hline Cacciatore et al (40) & 2013 & Sweden & 131 fathers & $>22$ weeks & $\begin{array}{l}0-4 \text { years }(n=99) \\
5-10 \text { years }(n=32)\end{array}$ & Questionnaire & A \\
\hline Lee (42) & 2012 & Australia & 14 mothers & $\begin{array}{l}20-24 \text { weeks }(n=9) \\
25-37 \text { weeks }(n=4) \\
1 \text { non-responder }\end{array}$ & 3-4 months & Questionnaire & $B$ \\
\hline Downe et al (43) & 2013 & UK & $\begin{array}{l}22 \text { mothers } \\
3 \text { couples }\end{array}$ & 24-42 weeks & $1-9$ years & Interview & A \\
\hline
\end{tabular}




\section{Table 2: Quantitative Studies: Heterogeneity of Study Designs, Analytical Strategies and Outcomes Measures}

\begin{tabular}{|c|c|c|c|}
\hline $\begin{array}{l}\text { Author/Yearl } \\
\text { Country }\end{array}$ & Focus & Design and Methodology & Analytic Strategy \\
\hline $\begin{array}{l}\text { Lasker and } \\
\text { Toedter, 1994, } \\
\text { USA(20) }\end{array}$ & $\begin{array}{l}\text { Interventions at time of } \\
\text { loss and associated } \\
\text { outcomes }\end{array}$ & $\begin{array}{l}\text { Longitudinal cohort study with } \\
\text { interviews at } 2 \text { months, } 1 \text { year and } \\
2 \text { years following loss }\end{array}$ & $\begin{array}{l}\text { Hypothesis testing with results } \\
\text { reported by four groups - pregnancy } \\
\text { loss, early fetal loss (16-26 weeks); } \\
\text { late fetal loss (>27 weeks) and } \\
\text { neonatal death }\end{array}$ \\
\hline
\end{tabular}

Rådested et al, Factors that may predic

1996, long-term psychologica

Sweden(21) complications

Rådested et al, Maternal views

1996 ,

Sweden(22)

Hughes et al

2002, UK (23)

Is seeing and holding

beneficial to

health of mother and

next-born child?

Surkan et al,

2008, Sweden

(24)

Associations between

infant bonding, materna

actions, and depressive

symptoms

Cacciatore et al, Seeing and holding and

2008,

Seeing and holdi
risk of anxiety

(25)

Turton et al,

2009, UK (26)
(23)
Seven-year follow-up of Nested case-control study
Main Outcome Measures

Findings

Satisfaction with general care at time of loss; satisfaction with specific intervention at time of loss; and grief outcomes over course of two years following loss

Retrospective case-control study Multivariate linear and other using national birth records and regression modelling techniques epidemiological methods

Postal questionnaire responses obtained as part of the above study $(21)$

Part of wider case-control study

Inferential statistics

Retrospective case-control study using national birth records and epidemiological methods

Multivariate linear regression modelling techniques

\section{Web questionnaire}

Multivariate linear and other regression modelling techniques

Inferential statistics
Anxiety related and depression related symptoms at around four years following loss

Not applicable

Maternal symptoms of during $3^{\text {rd trimester of pregnancy }}$

Time between delivery and seeing baby, held and/or staff at delivery

Anxiety and depression-related symptoms

Depression, post-traumatic stress disorder (PTSD) and partnership breakdown depression, anxiety, and PTSD caressed baby, time with baby,
Parents' who experienced late fetal loss (27+ weeks) who saw, touched/held or spent time alone with baby were significantly more satisfied than those who did not. There was no significant difference between those who did not see or did not touch/ hold baby at an earlier gestation.

Not seeing baby for as long as the mother wished was associated with increased risk of anxiety related and depressive related symptoms, suggesting that meeting and parting is important and should be strengthened to diminish the risk of long term psychological complications.

One third of women stated staff should have been more active in helping them meet their baby, but some (unclear how many) felt staff tried to force them to see and hold their baby when they were not ready for it.

Women who had held their stillborn baby were more depressed only saw the infant, while those who did not see Whe the baby were least lkely to be depressed. Women who had seen their stilborn infant had greater anx

Factors related to maternal depressive symptoms at 3 years' follow up were mother not being with the stillborn baby as long as desired, later birth order of the stillborn, and no subsequent pregnancy during the first 6 months after the event.

Seeing and holding the stillborn baby are associated with fewer anxiety and depressive symptoms among mothers of stillborn babies than not dis babies than not doing so, alhough this beneficial effect

Significantly higher levels of PTSD persisted in stillbirth group amongst women who had case-level PTSD seven years earlier. Partnership breakdown was associated with having held stillborn and having had case level PTSD. 
Rådested et al,

2009, Sweden

(27)

Long term outcomes of

mothers who have or

have not held their

stillborn baby

Erlandsson et al,

$2013(28)$

Way caregivers offer

opportunities to see and

hold impacts mothers

Crawley et al, Creating and sharing

2013 (29) memories following

mental health
Postal questionnaire responses

obtained as part of above study

(21)

Iferential statistics

Aniety, depression and

wellbeing

Web-questionnaire

imple descriptive and inferential

statistics

Regression analyses

Web-questionnaire
Maternal views and symptoms f depression, anxiety and PTSD
Holding a stillborn baby born after 37 weeks was found to be beneficial, whereas the effects of holding a baby born between 28 37 gestational weeks were uncertain. The attitude of staff influenced whether or not the mother held her stillborn baby.

Mothers presented with their stillborn baby as a normal part of birth (without being asked if they wanted to see) felt more natural, good, comfortable and less frightened than those who were asked to choose.

All mothers saw their babies and nearly all held them with wide variations in mental health scores. There was no association between making memories and PTSD, anxiety or depressive symptoms, but sharing memories was associated with fewer symptoms of PTSD. 